\title{
Pancreatic insulin release in vitamin C-deficient senescence marker protein-30/gluconolactonase knockout mice
}

\author{
Takafumi Senmaru, ${ }^{1}$ Masahiro Yamazaki, ${ }^{1}$ Hiroshi Okada, ${ }^{1}$ Mai Asano, ${ }^{1}$ Michiaki Fukui,, ${ }^{1}$ Naoto Nakamura, ${ }^{1}$ \\ Hiroshi Obayashi, ${ }^{2}$ Yoshitaka Kondo, ${ }^{3}$ Naoki Maruyama, ${ }^{3}$ Akihito Ishigami $^{3}$ and Goji Hasegawa ${ }^{1, *}$ \\ 1Department of Endocrinology and Metabolism, Kyoto Prefectural University of Medicine Graduate School of Medical Science, \\ 465 Kajii-cho, Hirokoji, Kamikyo-ku, Kyoto 602-8556, Japan \\ 2Institute of Bio-Response Informatics, 22-15, Yousai, Momoyama-cho, Fushimi-ku, Kyoto 612-8016, Japan \\ ${ }^{3}$ Aging Regulation, Tokyo Metropolitan Institute of Gerontology, 35-2 Sakae-cho, Itabashi-ku, Tokyo 173-0015, Japan
}

(Received 25 April, 2011; Accepted 8 May, 2011; Published online 1 November, 2011)

\begin{abstract}
We recently identified senescence marker protein-30 as the lactonehydrolyzing enzyme gluconolactonase, which is involved in vitamin $C$ biosynthesis. In this study, we investigated the effects of vitamin $C$ on insulin secretion from pancreatic $\beta$-cells using senescence marker protein-30/gluconolactonase knockout mice. In intraperitoneal glucose tolerance tests, vitamin C-deficient senescence marker protein-30/gluconolactonase knockout mice demonstrated impaired glucose tolerance with significantly lower blood insulin levels at 30 and 120 min post-challenge than in wild type mice $(p<0.01-0.05)$. In contrast, vitamin C-sufficient senescence marker protein-30/gluconolactonase knockout mice demonstrated significantly higher blood glucose and lower insulin only at the $\mathbf{3 0 ~} \mathrm{min}$ post-challenge time point $(p<0.05)$. Senescence marker protein-30/ gluconolactonase knockout mice showed enhanced insulin sensitivity regardless of vitamin C status. Static incubation of islets revealed that $20 \mathrm{mM}$ glucose-stimulated insulin secretion and islet ATP production were significantly decreased at $60 \mathrm{~min}$ only in vitamin C-deficient SMP30/GNL knockout mice relative to wild type mice $(p<0.05)$. These results indicate that the site of vitamin $C$ action lies between glycolysis and mitochondrial oxidative phosphorylation, while SMP30 deficiency itself impairs the distal portion of insulin secretion pathway.
\end{abstract}

Key Words: vitamin C, insulin, islet, Senescence marker protein-30, gluconolactonase

$\mathrm{S}$ enescence marker protein-30 (SMP30), a 34-kDa protein originally identified in rat liver, is a novel molecule with expression that decreases with age in a sex-independent manner. ${ }^{(1,2)}$ Recently, we determined that SMP30 is gluconolactonase (GNL), which is involved in L-ascorbic acid biosynthesis in mammals. Humans, nonhuman primates, and guinea pigs are unable to synthesize vitamin C (VC) in vivo because there are many mutations in their gulonolactone oxidase gene, which catalyzes the conversion of L-gulono- $\gamma$-lactone to L-ascorbic acid. ${ }^{(3)}$ Although the physiological function of SMP30/GNL is still not entirely clear, our studies using SMP30/GNL knockout (KO) mice have revealed that a reduction in SMP30/GNL expression may contribute to ageassociated deterioration of cellular function and the enhanced susceptibility to harmful stimuli in aged tissue. ${ }^{(4-11)}$ SMP30/GNL $\mathrm{KO}$ mice cannot synthesize ascorbic acid and display symptoms of scurvy when fed a VC-deficient diet. ${ }^{(3,12,13)}$ Furthermore, SMP30/ GNL KO mice have been used for the study of VC movement and regulation of $\mathrm{VC}$ transporter expression. ${ }^{(14-16)}$

Guinea pigs have long been used for $\mathrm{VC}$ research, and the essential role of $\mathrm{VC}$ in the release of insulin from pancreatic islets was shown using scorbutic guinea pigs. ${ }^{(17-22)}$ However, there have been no previous reports on the role of VC in insulin secretion in other animal species. In the present study, we demonstrate impaired glucose tolerance in vivo and abnormal insulin release from pancreatic islets in VC-deficient SMP30/GNL KO mice.

\section{Materials and Methods}

Animals. SMP30/GNL KO mice were generated as previously described by gene targeting in C57BL/6 mice. ${ }^{(4)}$ Male mice were used for all studies. All studies were performed using agematched, wild type (WT) C57BL/6CrSlc mice (Shimizu Laboratory Supplies Co., Ltd., Kyoto, Japan) as controls. Mice were fed VCdeficient chow (CL-2; CLEA Japan, Tokyo Japan) for 8 weeks starting at 7 weeks of age and then divided into two groups: a VCsupplemented $(\mathrm{VC}(+))$ group, and a VC-deficient (VC $(-)$ ) group. The VC $(+)$ group had free access to water containing $1.5 \mathrm{~g} / \mathrm{L} \mathrm{VC}$ in $10 \mu \mathrm{M}$ ethylenediaminetetraacetic acid (EDTA; $\mathrm{pH}$ 8.0), whereas the VC (-) group had free access to water containing $37.5 \mathrm{mg} / \mathrm{L}$ $\mathrm{VC}$ and $10 \mu \mathrm{M}$ EDTA. Under VC $(-)$ conditions, SMP30/GNL KO mice do not manifest symptoms of scurvy and their body weight gain is similar to that of WT mice. The water was changed every 3 days until the experiment ended. Mice had free access to food, and were maintained on a 12-h light/dark cycle in a temperature-controlled room. At the end of the experiment, mice were killed by an overdose of sodium aminobarbital after an overnight fast, and the pancreas and liver were removed. All experimental procedures were approved by the Committee for Animal Research, Kyoto Prefectural University of Medicine.

Analytical procedures and glucose and insulin tolerance tests. Blood glucose levels were measured using a glucometer (GLUTEST ACE, Sanwa Kagaku Kenkyusho Co., Ltd., Nagoya, Japan). Intraperitoneal glucose ( $2 \mathrm{~g} / \mathrm{kg}$ body weight) and insulin $(0.75 \mathrm{U} / \mathrm{kg}$ body weight $)$ tolerance tests were performed after $16 \mathrm{~h}$ and $7 \mathrm{~h}$ fasts, respectively, and blood glucose was measured at the indicated time points. To measure insulin release during glucose tolerance testing, plasma collected at the 0,30 , and $120 \mathrm{~min}$ time points was analyzed using an insulin enzyme immunoassay system, the Morinaga Ultra Sensitive Mouse Insulin Assay kit (Morinaga Institute of Biological Science, Inc., Kanagawa, Japan).

Measurement of pancreatic insulin content. Pancreatic insulin content was determined as previously described. ${ }^{(23)}$ Briefly, a portion of the pancreatic tail was homogenized in acidic ethanol

*To whom correspondence should be addressed. E-mail: goji@koto.kpu-m.ac.jp 
$\left(0.18 \mathrm{~mol} / \mathrm{L} \mathrm{HCl}\right.$ in $95 \%$ ethanol), and extracted for $24 \mathrm{~h}$ at $4^{\circ} \mathrm{C}$. The homogenate was then centrifuged at $2,000 \times \mathrm{g}$ for $15 \mathrm{~min}$. Insulin levels in the supernatant were assayed as described above.

Measurement of total vitamin C levels in the liver. Livers were homogenized in 14 volumes of $5.4 \%$ metaphosphonic acid, and then the homogenate was centrifuged at $21,000 \times \mathrm{g}$ for $15 \mathrm{~min}$ at $4^{\circ} \mathrm{C}$. Ascorbic acid in samples was treated with $350 \mathrm{mM}$ tris(2-carboxyethyl)phosphine hydrochloride to reduce the dehydroascorbic acid to ascorbic acid and analyzed by HPLC using an Atlantis dC18 $5 \mu \mathrm{m}$ column $(4.6 \times 150 \mathrm{~mm}$, Nihon Waters, Tokyo, Japan). ${ }^{(24)}$ The mobile phase was $50 \mathrm{mM}$ phosphate buffer (pH 2.8), $0.2 \mathrm{~g} / \mathrm{L}$ EDTA, and $2 \%$ methanol at a flow rate of $1.3 \mathrm{~mL} / \mathrm{min}$, and electrical signals were recorded using an electrochemical detector with a glassy carbon electrode at $+0.6 \mathrm{~V}$.

Static insulin secretion from isolated islets. Pancreatic islets were isolated from $\mathrm{VC}(+)$ and $\mathrm{VC}(-) \mathrm{SMP} 30 / \mathrm{GNL} \mathrm{KO}$ and VC (-) WT mice. Islets were isolated using collagenase (Type V collagenase, Sigma, St. Louis, MO), digested in Hanks' buffer, followed by separation of islets from exocrine tissue in a Histopaque (Histopaque 1077, Sigma) gradient. ${ }^{(25)}$ Islets of similar size were hand-picked under a stereomicroscope into triplicate groups $(n=5)$ of 5 islets each. The islets were preincubated for $60 \mathrm{~min}$ at $37^{\circ} \mathrm{C}$ in Krebs-Ringer bicarbonate HEPES buffer (KRBH, equilibrated with $95 \% \mathrm{O}_{2}$ and $5 \% \mathrm{CO}_{2}, \mathrm{pH} 7.4$ ) supplemented with $2 \mathrm{mg} / \mathrm{ml}$ BSA (fraction V, Sigma) and $2 \mathrm{mM}$ glucose. After preincuation, the islets were incubated with $200 \mu \mathrm{l}$ of the same buffer for $60 \mathrm{~min}$. After samples were removed from the buffer for measurement of insulin, they were incubated in $20 \mathrm{mM}$ glucose for another $60 \mathrm{~min}$, and then the supernatant was collected. All samples were stored at $-80^{\circ} \mathrm{C}$ until the insulin assay.

ATP measurement from isolated islets. Cultured islets were preincubated at $37^{\circ} \mathrm{C}$ for $60 \mathrm{~min}$ in $\mathrm{KRBH}$ with $2 \mathrm{mM}$ glucose and then triplicate batches of 10 islets were incubated in 2 or $20 \mathrm{mM}$ glucose for another $60 \mathrm{~min}$. ATP was extracted from islets using the methods described by Uchizono et al. ${ }^{(26)}$ ATP levels were measured using the Enliten ATP Assay System (Promega, WI) with a bioluminometer (GloMax 20/20n Luminometer, Promega).

Statistical analysis. Data are expressed as means \pm SE. Significance was determined by one-way ANOVA with Dunn's multiple comparisons post-hoc. A two-way ANOVA was used to compare glucose and insulin levels at the same time point for the intraperitoneal glucose tolerance test. $p<0.05$ was considered to be significant.

\section{Results}

Body weight, blood glucose, pancreatic insulin content, and total liver vitamin C. There were no differences in body weight, blood glucose, or pancreatic insulin content among the four experimental groups (Table 1). However, as expected, total liver VC in VC (-) SMP30/GNL KO mice were dramatically lower than that in the other three groups. These results indicate that VC deficiency (ad libitum access to water containing $37.5 \mathrm{mg} / \mathrm{L} \mathrm{VC}$ ) did not affect normal growth as assessed by body weight gain.
Furthermore, VC supplementation (ad libitum access to water containing $1.5 \mathrm{~g} / \mathrm{L} \mathrm{VC}$ ) increased VC levels in SMP30/GNL KO mice to a level comparable to that in WT mice (Table 1).

Intraperitoneal glucose tolerance test. Blood glucose levels $30 \mathrm{~min}$ after glucose administration were significantly higher in VC $(+)$ SMP30/GNL KO mice than in VC $(-)$ or VC $(+)$ WT mice $(p<0.05$, Fig. 1). In addition, blood glucose levels in VC (-) SMP30/GNL KO mice 30, 60, and 120 min after glucose administration were significantly higher than those of WT mice in either group ( $p<0.01$, Fig. 1). However, there were no significant differences in blood glucose levels between VC $(-)$ and VC $(+)$ SMP30/GNL KO mice at any time point. VC supplementation did not affect glucose tolerance in WT mice. A significant increase in area under the curve (AUC, $0-120 \mathrm{~min}$ ) was detected only in VC (-) SMP30/GNL KO mice when compared to VC (-) and VC (+) WT mice $(p<0.01$, Fig. 1). No significant difference in AUC was detected between VC $(-)$ and VC (+) SMP30/GNL KO mice.

There were no significant differences in fasting insulin levels among the four groups. However, insulin levels $30 \mathrm{~min}$ postglucose were significantly lower in VC (-) and VC (+) SMP30/ GNL KO mice than in either group of WT mice $(p<0.01$ and $<0.05$, respectively, Fig. 2). Insulin levels $120 \mathrm{~min}$ post-glucose were lower in VC (-) SMP30/GNL KO mice than in the other three groups; however, the difference was significant only when compared to VC $(+)$ WT mice $(p<0.05$, Fig. 2$)$. AUC $(0-120 \mathrm{~min})$ for VC (-) SMP30/GNL KO mice was significantly lower than that for VC $(-)$ and VC $(+)$ WT mice $(p<0.05$, Fig. 2$)$; however, while VC (+) SMP30/GNL KO mice also showed a trend towards decreased AUC, it was not significant.

Insulin tolerance test. We next assessed insulin sensitivity using an insulin tolerance test. Blood glucose levels in both groups of SMP30/GNL KO mice were significantly lower than those in WT mice after 30 and $60 \mathrm{~min}$, indicating high peripheral insulin sensitivity (Fig. 3). In VC (-) SMP30/GNL KO mice, the decrease in blood glucose levels was significant at 30 and $60 \mathrm{~min}$. VC deficiency did not induce significant changes in insulin sensitivity in SMP30/GNL KO or WT mice.

Measurement of insulin secretion and ATP from isolated islets. To confirm $\beta$-cell dysfunction in SMP30/GNL KO mice, we measured glucose-stimulated insulin secretion in isolated islets. As described above, VC deficiency did not affect liver $\mathrm{VC}$ content or glucose tolerance in WT mice, so we used islets from VC (-) WT mice as a control. Similar to the in vivo results, insulin secretion from VC (-) SMP30/GNL KO islets incubated in $20 \mathrm{mM}$ glucose for 60 min was significantly reduced compared to that from VC $(+)$ SMP30/GNL KO and WT islets $(p<0.05$, Fig. 4). The insulin secretory response in VC (+) SMP30/GNL KO islets was similar to that in WT islets (Fig. 4). This finding may indicate that impaired insulin secretion in response to glucose in VC (+) SMP30/GNL KO islets is due to selective impairment of the early phase of insulin secretion $(\sim 30 \mathrm{~min})$ but that by $60 \mathrm{~min}$ after glucose stimulation this impairment is no longer evident. To support this assumption, a previous report by our group demonstrated significantly lower insulin secretion in response to $20 \mathrm{mM}$

Table 1. Body weight, blood glucose levels, pancreatic insulin content, and liver vitamin C content after 8 weeks of vitamin C deficiency (15 weeks of age)

\begin{tabular}{|c|c|c|c|c|}
\hline & \multicolumn{2}{|c|}{$\mathrm{KO}$} & \multicolumn{2}{|c|}{ WT } \\
\hline & VC (+) & VC (-) & VC (+) & VC (-) \\
\hline Body weight $(g)$ & $29.6 \pm 0.6$ & $31.4 \pm 0.6$ & $29.6 \pm 0.9$ & $30.1 \pm 0.6$ \\
\hline Fasting blood glucose (mg/dl) & $99.7 \pm 6.0$ & $86.9 \pm 5.7$ & $82.6 \pm 8.1$ & $88.0 \pm 3.1$ \\
\hline Fed blood glucose (mg/dl) & $145.1 \pm 7.8$ & $160.7 \pm 6.2$ & $142.7 \pm 7.6$ & $163.6 \pm 7.3$ \\
\hline Pancreatic insulin content ( $\mu \mathrm{g} / \mathrm{g}$ tissue) & $44.4 \pm 5.3$ & $41.9 \pm 3.4$ & $38.6 \pm 5.9$ & $38.3 \pm 4.9$ \\
\hline Vitamin C content, liver ( $\mu \mathrm{g} / \mathrm{g}$ tissue) & $143.7 \pm 7.7$ & $9.9 \pm 1.3^{*}$ & $169.4 \pm 9.9$ & $160.2 \pm 8.5$ \\
\hline
\end{tabular}

KO: SMP30/GNL knockout mice. WT: wild type mice. VC (+): vitamin C-supplemented. VC (-): vitamin C-deficient. * $p<0.01$ vs VC (+) KO, VC (+) WT, and VC (-) WT. Data are means \pm SE from seven mice. 

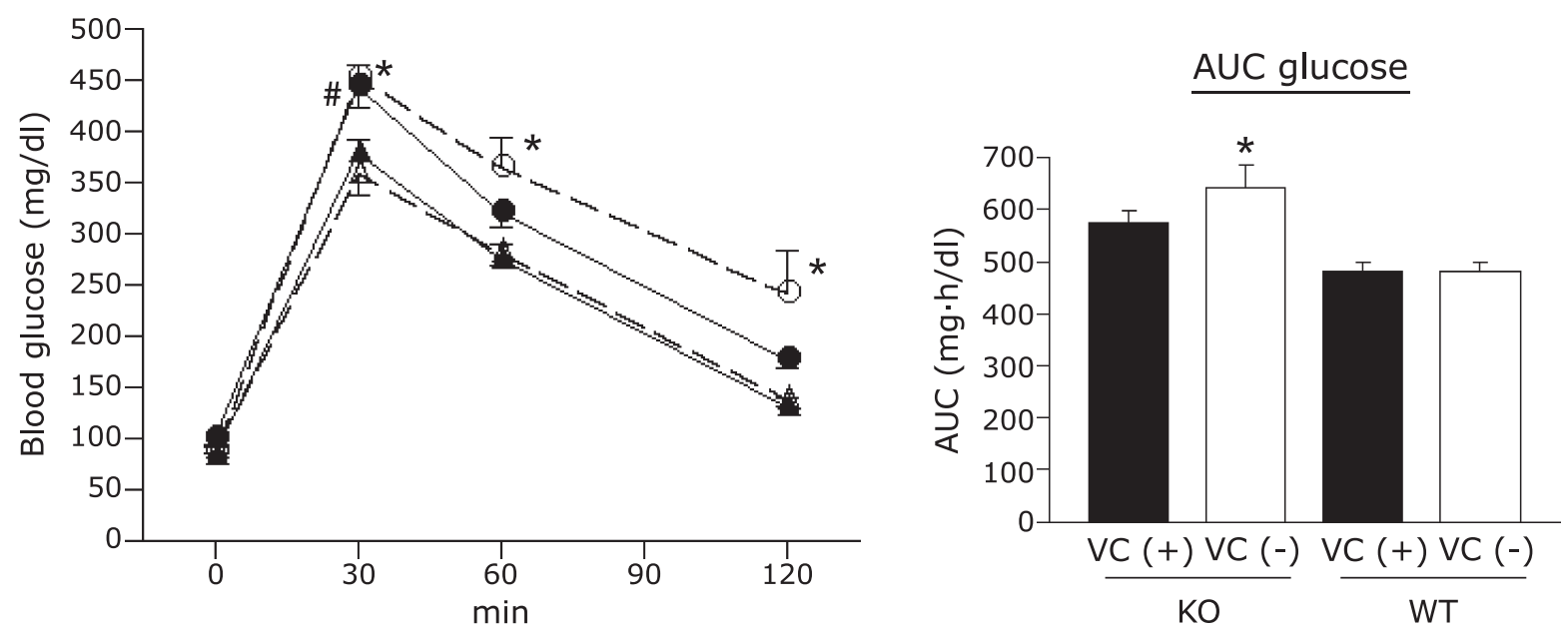

Fig. 1. Blood glucose levels in the intraperitoneal glucose tolerance test at 15 weeks of age. $\bigcirc \mathrm{VC}(+)$ SMP30/GNL knockout (KO), $\bigcirc$ VC ( - ) SMP30/GNL knockout (KO), $\Delta$ VC (+) wild type (WT), $\triangle$ VC (-) wild type (WT). * ${ }^{*}<0.01$ VC (-) KO vs VC (-) WT and VC (+) WT. VC: vitamin C, VC (+): free access to water containing $1.5 \mathrm{~g} / \mathrm{L}$ VC for 8 weeks from 7 weeks of age, VC (-): free access to water containing $37.5 \mathrm{mg} / \mathrm{L}$ VC for 8 weeks from 7 weeks of age, AUC: area under curve. ${ }^{~} p<0.05$ VC (-) KO vs VC (-) WT and VC (+) WT. Data are means \pm SE $(n=7)$.
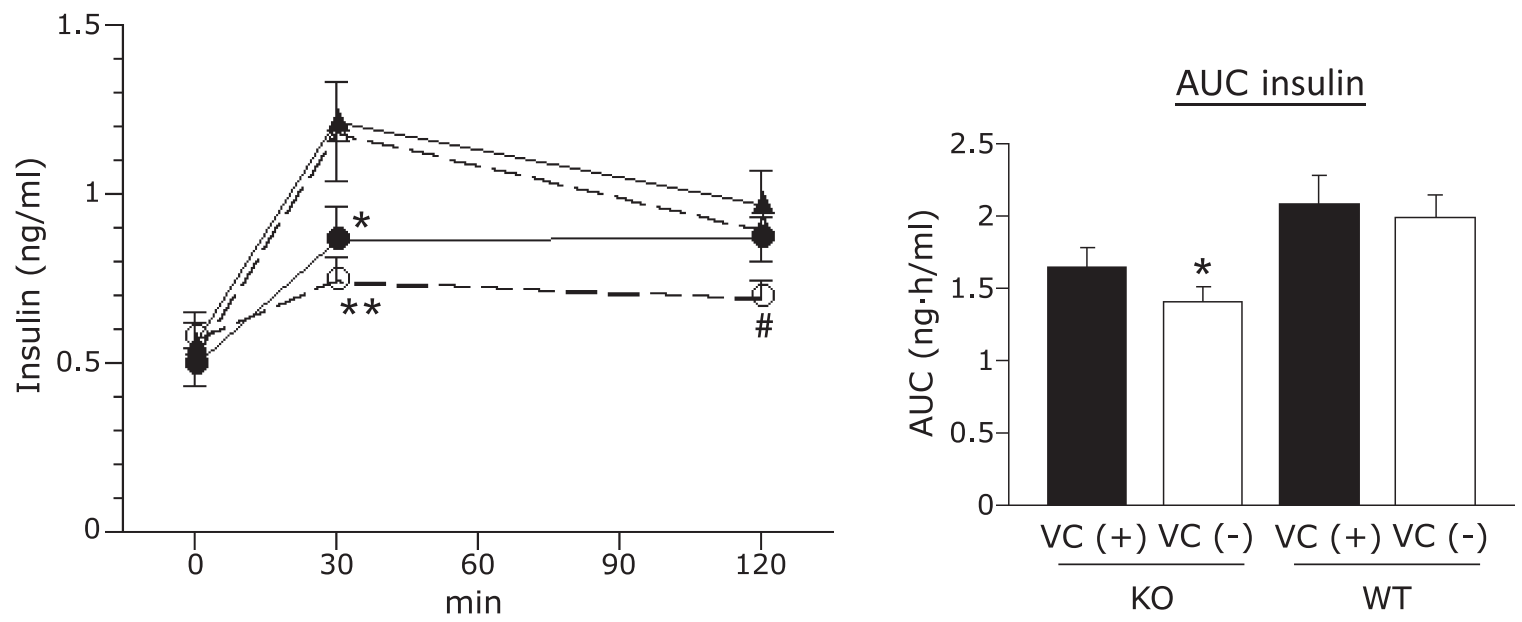

Fig. 2. Blood insulin levels in the intraperitoneal glucose tolerance test at 15 weeks of age. - VC (+) SMP30/GNL knockout (KO), $\bigcirc$ VC (-) SMP30/ GNL knockout (KO), $\Delta$ VC (+) wild type (WT), $\triangle$ VC (-) wild type (WT). VC: vitamin C, VC (+): free access to water containing $1.5 \mathrm{~g} / \mathrm{L}$ VC for 8 weeks from 7 weeks of age, VC (-): free access to water containing $37.5 \mathrm{mg} / \mathrm{L}$ VC for 8 weeks from 7 weeks of age, AUC: area under curve. ${ }^{*} p<0.05$, $* * p<0.01$ vs VC (-) WT and VC (+) WT. ${ }^{*} p<0.05$ vs VC (+) WT. Data are means \pm SE $(n=7)$

glucose after $15 \mathrm{~min}$ in islets from VC-supplemented SMP30/ GNL KO mice compared to WT mice. ${ }^{(10)}$

There were no significant differences in islet ATP content in $2 \mathrm{mM}$ glucose among the three groups. ATP content in $20 \mathrm{mM}$ glucose was significantly decreased in VC (-) SMP30/GNL KO islets compared to VC $(+)$ SMP30/GNL KO or WT islets $(p<0.05)$. ATP content in $20 \mathrm{mM}$ glucose in VC $(+)$ SMP30/GNL $\mathrm{KO}$ islets was similar to that in WT islets (Fig. 5).

\section{Discussion}

This report has shown that, in SMP30/GNL KO mice, VC deficiency without obvious signs of scurvy worsened glucose tolerance and impaired insulin secretion after a glucose load. Our in vitro data from isolated islets confirmed that VC deficiency was responsible for the reduced insulin secretory response to glucose. Furthermore, the observed decrease in glucose-stimulated ATP generation in pancreatic islets indicates that the site of $\mathrm{VC}$ action lies between glycolysis and mitochondrial oxidative phosphorylation. The modestly impaired glucose tolerance with an impairment of acute insulin secretion seen here in VC-supplemented SMP30/ GNL KO mice is comparable to that in our previous report, which demonstrated the role of SMP30/GNL in glucose homeostasis without looking at the effects of VC deficiency. ${ }^{(10)}$

The essential role of VC in glucose-stimulated insulin secretion was originally reported by Sigal and King, ${ }^{(17)}$ and Banerjee, ${ }^{(18)}$ who looked at scorbutic guinea pigs. In a subsequent study, it was shown that decreased insulin release from scorbutic islets was not due to decreased insulin synthesis but rather due to abnormal insulin secretion. ${ }^{(19,20)}$ Further studies have demonstrated that 


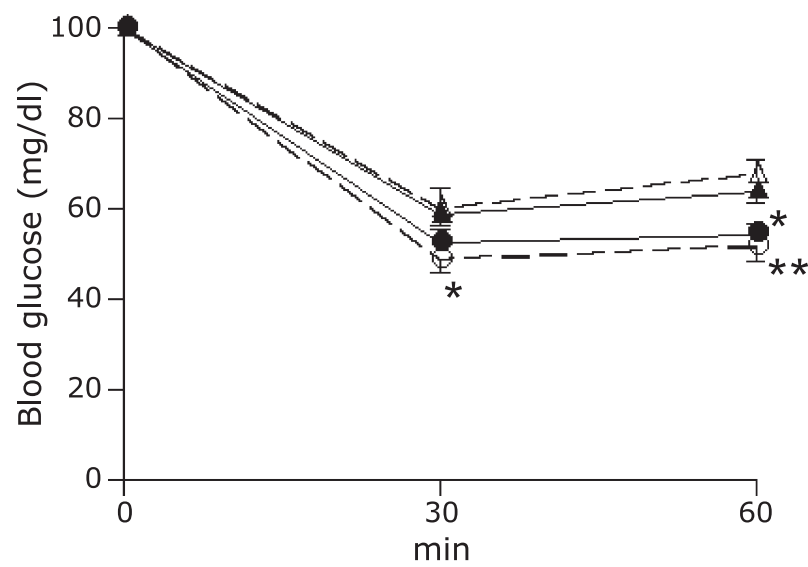

Fig. 3. Intraperitoneal insulin tolerance test at 15 weeks of age. Data are expressed as \% of basal (0 min) glucose levels. VC (+) SMP30/GNL knockout (KO), $\bigcirc$ VC (-) SMP30/GNL knockout (KO), $\Delta$ VC (+) wild type (WT), $\triangle$ VC (-) wild type (WT). VC: vitamin C, VC (+): free access to water containing $1.5 \mathrm{~g} / \mathrm{L}$ VC for 8 weeks from 7 weeks of age, VC (-): free access to water containing $37.5 \mathrm{mg} / \mathrm{L}$ VC for 8 weeks from 7 weeks of age. ${ }^{*} p<0.05,{ }^{*} p<0.01$ vs VC (-) WT and VC (+) WT. Data are means \pm SE $(n=7)$.

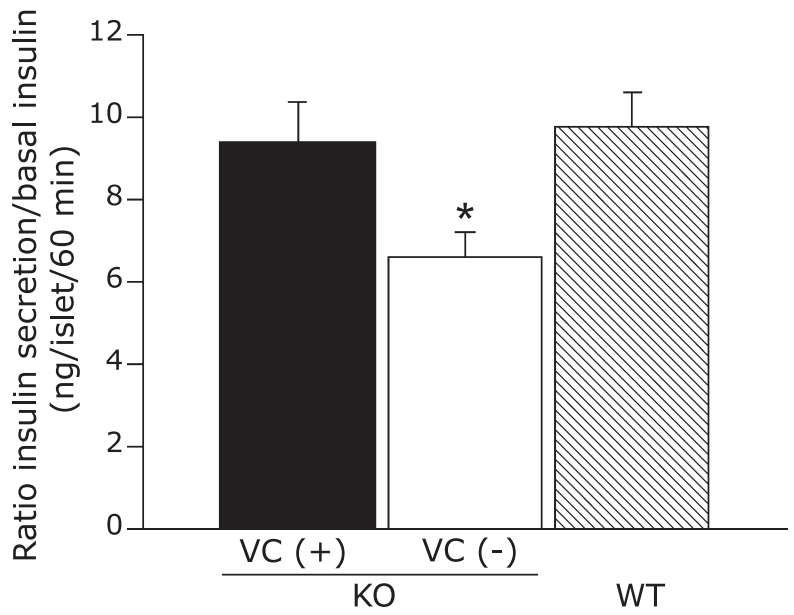

Fig. 4. Static islet incubation for $60 \mathrm{~min}$ in $20 \mathrm{mM}$ glucose. Data are expressed as ratios of $60 \mathrm{~min}$ insulin to basal insulin (pg/islet/60 min). KO: SMP30/GNL knockout mice at 15 weeks of age, WT: wild type mice at 15 weeks of age, VC: vitamin C, VC (+): free access to water containing $1.5 \mathrm{~g} / \mathrm{L}$ VC for 8 weeks from 7 weeks of age, VC (-): free access to water containing $37.5 \mathrm{mg} / \mathrm{L}$ VC for 8 weeks from 7 weeks of age. ${ }^{*} p<0.05$ vs VC $(+) \mathrm{KO}$ and WT. Data are means \pm SE $(n=5)$.

$\mathrm{VC}$ is an essential cofactor for the activation of mitochondrial glycerol-3-phosphate dehydrogenase (mGPDH), a key enzyme for the glycerol phosphate NADH shuttle in pancreatic $\beta$-cells. They assumed that $\mathrm{mGPDH}$ inactivation due to $\mathrm{VC}$ deficiency would cause a reduction in shuttling of cytosolic NADH generated from glycolysis and pyruvate into mitochondria, leading to a reduction in ATP generation and thereby reducing insulin release. ${ }^{(21,22)}$ The present data from our study of VC-deficient SMP30/GNL KO mice are consistent with these previous studies in scorbutic guinea pigs.

Because SMP30 is abundant in the kidney and also present in lesser amounts in other organs, ${ }^{(27)}$ this protein is presumed to have some function other than VC synthesis, which does not occur at

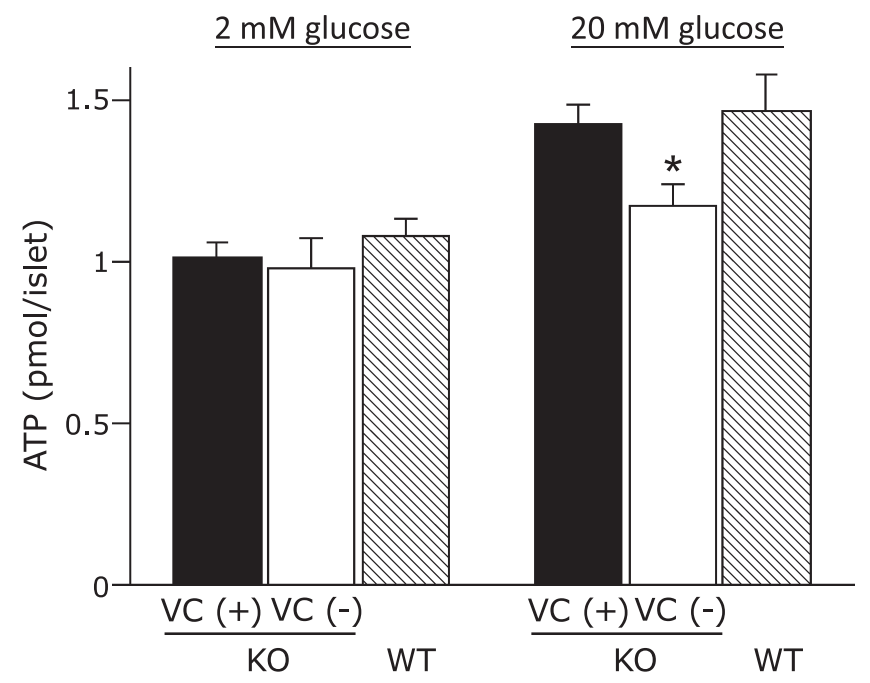

Fig. 5. Islet ATP content in $2 \mathrm{mM}$ and $20 \mathrm{mM}$ glucose. KO: SMP30/GNL knockout mice at 15 weeks of age, WT: wild type mice at 15 weeks of age, VC: vitamin C, VC (+): free access to water containing $1.5 \mathrm{~g} / \mathrm{L} \mathrm{VC} \mathrm{for}$ 8 weeks from 7 weeks of age, VC $(-)$ : free access to water containing $37.5 \mathrm{mg} / \mathrm{L}$ VC for 8 weeks from 7 weeks of age. ${ }^{*} p<0.05$ vs VC (+) KO and WT. Data are means \pm SE $(n=5)$.

all these sites. Our previous study of VC-supplemented SMP30/ GNL KO mice suggested that SMP30 deficiency itself induced dysregulation of $\mathrm{Ca}^{2+}$ homeostasis, resulting in impairment of glucose-induced $\mathrm{Ca}^{2+}$ influx and of $\mathrm{Ca}^{2+}$-dependent signaling pathways, which are involved in the peripheral portion of the insulin secretion pathway. These results suggest that SMP30 could be implicated in the impairment of $\beta$-cell function with age in humans. ${ }^{(10)}$ Therefore, it should be noted that the decreased insulin secretion demonstrated here in VC-deficient SMP30/GNL KO mice is a consequence of impairment of both the peripheral and proximal portions of the insulin secretion pathway.

Surprisingly, there have been no previous reports on the effects of VC deficiency on insulin sensitivity. In the present study, despite impaired glucose tolerance, SMP30/GNL KO mice showed greater insulin sensitivity, regardless of VC status. Although the mechanism has not been studied, inactivation of $\mathrm{mGPDH}$ due to VC deficiency could partially explain this phenomenon, considering that previous reports showed that mGPDH KO mice manifest increased insulin sensitivity and impaired insulin secretion, similar to SMP30/GNL KO mice. ${ }^{(28,29)}$

The inability of guinea pigs to synthesize VC due to mutations in the L-gulono-g-lactone oxidase gene is well known. ${ }^{(30)}$ Because they share this trait with humans, guinea pigs have long been used for $\mathrm{VC}$ research. Most of our knowledge of the role of $\mathrm{VC}$ in insulin secretion and glucose tolerance in vivo has come from studies of VC-deficient guinea pigs. ${ }^{(17-22)}$ This is the first study examining insulin secretion in a VC-deficient mouse model. These laboratory animals have advantages over guinea pigs in terms of breeding, care, and size. L-gulono-g-lactone oxidase $\mathrm{KO}$ mice, which cannot synthesize VC in vivo, represent another VCdeficient mouse model. ${ }^{(31)}$

In summary, VC-deficient SMP30/GNL KO mice have modestly impaired glucose tolerance with impaired acute insulin secretion due to decreased glucose-stimulated ATP production in $\beta$-cells. These results suggest that the site of $\mathrm{VC}$ action is between glycolysis and mitochondrial oxidative phosphorylation. SMP30/GNL KO mice are a useful VC-deficient animal model, and further studies will bring us new insights into the mechanism of insulin secretion in pancreatic $\beta$-cells. 


\section{Acknowledgments}

This study was supported by a Grant-in-Aid for Scientific Research (C) (No. 20591066 and 23591317 to GH). We thank Hiroko Kawamura, Sayoko Horibe and Sanae Utena for secretarial assistance. Vitamin C powder was kindly provided by DSM Nutrition Japan.

\section{Abbreviations}

ATP adenosine triphosphate

BSA bovine serum albumin

EDTA ethylenediaminetetraacetic acid

GNL gluconolactonase

HEPES 4-(2-hydroxyethyl)-1-piperazineethanesulfonic acid

HPLC high performance liquid chromatography

KO knockout

VC vitamin C

mGPDH mitochondrial glycerol-3-phosphate dehydrogenase

NADH nicotinamide adenine dinucleotide

WT wild type

\section{References}

1 Fujita T, Uchida K, Maruyama N. Purification of senescence marker protein30 (SMP30) and its androgen-independent decrease with age in the rat liver. Biochim Biophys Acta 1992; 1116: 122-128.

2 Ishigami A, Maruyama N. Significance of SMP30 in gerontology. Geriatr Gerontol Int 2007; 7: 316-325.

3 Kondo Y, Inai Y, Sato Y, et al. Senescence marker protein 30 functions as gluconolactonase in L-ascorbic acid biosynthesis, and its knockout mice are prone to scurvy. Proc Natl Acad Sci USA 2006; 103: 5723-5728.

4 Ishigami A, Fujita T, Handa S, et al. Senescence marker protein-30 knockout mouse liver is highly susceptible to tumor necrosis factor-alpha- and Fasmediated apoptosis. Am J Pathol 2002; 161: 1273-1281.

5 Ishigami A, Kondo Y, Nanba R, et al. SMP30 deficiency in mice causes an accumulation of neutral lipids and phospholipids in the liver and shortens the life span. Biochem Biophys Res Commun 2004; 315: 575-580.

6 Mori T, Ishigami A, Seyama K, et al. Senescence marker protein-30 knockout mouse as a novel murine model of senile lung. Pathol Int 2004; 54: 167-173.

7 Sato T, Seyama K, Sato Y, et al. Senescence marker protein-30 protects mice lungs from oxidative stress, aging, and smoking. Am J Respir Crit Care Med 2006; 174: 530-537.

8 Son TG, Zou Y, Jung KJ, et al. SMP30 deficiency causes increased oxidative stress in brain. Mech Ageing Dev 2006; 127: 451-457.

9 Yumura W, Imasawa T, Suganuma S, et al. Accelerated tubular cell senescence in SMP30 knockout mice. Histol Histopathol 2006; 21: 1151-1156.

10 Hasegawa G, Yamasaki M, Kadono M, et al. Senescence marker protein-30/ gluconolactonase deletion worsens glucose tolerance through impairment of acute insulin secretion. Endocrinology 2010; 151: 529-536.

11 Park H, Ishigami A, Shima T, et al. Hepatic senescence marker protein-30 is involved in the progression of nonalcoholic fatty liver disease. J Gastroenterol 2010; 45: 426-434.

12 Kondo Y, Sasaki T, Sato Y, et al. Vitamin C depletion increases superoxide generation in brains of SMP30/GNL knockout mice. Biochem Biophys Res Commun 2008; 377: 291-296.

13 Koike K, Kondo Y, Sekiya M, et al. Complete lack of vitamin C intake generates pulmonary emphysema in senescence marker protein-30 knockout mice. Am J Physiol Lung Cell Mol Physiol 2010; 298: L784-L792.

14 Furusawa H, Sato Y, Tanaka Y, et al. Vitamin C is not essential for carnitine biosynthesis in vivo: verification in vitamin C-depleted senescence marker protein-30/gluconolactonase knockout mice. Biol Pharm Bull 2008; 31: $1673-1679$.

15 Amano A, Aigaki T, Maruyama N, Ishigami A. Ascorbic acid depletion enhances expression of the sodium-dependent vitamin $\mathrm{C}$ transporters, SVCT1 and SVCT2, and uptake of ascorbic acid in livers of SMP30/GNL knockout mice. Arch Biochem Biophys 2010; 496: 38-44.

16 Iwama M, Shimokado K, Maruyama N, Ishigami A. Time course of vitamin C distribution and absorption after oral administration in SMP30/GNL knockout mice. Nutrition 2011; 27: 471-478.
17 Sigal A, King CG. The relationship of vitamin C to glucose tolerance in the guinea pig. J Biol Chem 1936; 116: 489-492.

18 Banerjee S, Deb C, Belavady B. Effect of scurvy on glutathione and dehydroascorbic acid in guinea pig tissues. J Biol Chem 1952; 195: 271-276.

19 Wells WW, Dou CZ, Dybas LN, Jung CH, Kalbach HL, Xu DP. Acorbic acid is essential for the release of insulin from scorbutic guinea pig pancreatic islets. Proc Natl Acad Sci USA 1995; 92: 11869-11873.

20 Dou C, Xu DP, Wells WW. Studies on the essential role of ascorbic acid in the energy dependent release of insulin from pancreatic islets. Biochem Biophys Res Commun 1997; 231: 820-822.

21 Jung $\mathrm{CH}$, Wells WW. Ascorbic acid is a stimulatory cofactor for mitochondrial glycerol-3-phosphate dehydrogenase. Biochem Biophys Res Commun 1997; 239: 457-462.

22 Wells WW, Xu DP, Washburn MP, Cirrito HK, Olson LK. Polyhydroxybenzoates inhibit ascorbic acid activation of mitochondrial glycerol-3phosphate dehydrogenase: implications for glucose metabolism and insulin secretion. J Biol Chem 2001; 276: 2404-2410.

23 Hasegawa G, Mori H, Sawada M, et al. Dietary treatment ameliorates overt diabetes and decreased insulin secretion to glucose induced by overeating in impaired glucose tolerant mice. Horm Metab Res 1990; 22: 408-412.

24 Sato $\mathrm{Y}$, Uchiki T, Iwama M, Kishimoto $\mathrm{Y}$, Takahashi R, Ishigami A. Determination of dehydroascorbic acid in mouse tissues and plasma by using tris(2-carboxyethyl)phosphine hydrochloride as reductant in metaphosphoric acid/ethylenediaminetetraacetic acid solution. Biol Pharm Bull 2010; 33: 364-369.

25 Lacy PE, Kostianovsky M. Method of the isolation of intact islets of Langerhans from the rat pancreas. Diabetes 1967; 16: 35-39.

26 Uchizono Y, Iwase M, Nakamura U, Sasaki N, Goto D, Iida M. Tacrolimus impairment of insulin secretion in isolated rats islets occurs at multiple distal sites in stimulus-secretion coupling. Endocrinology 2004; 145: 2264-2272.

27 Fujita T, Shirasawa T, Uchida K, Maruyama N. Isolation of cDNA clone encoding rat senescence marker protein-30 (SMP30) and its tissue distribution. Biochim Biophys Acta 1992; 1132: 297-305.

28 Barberá A, Gudayol M, Eto $\mathrm{K}$, et al. A high carbohydrate diet does not induce hyperglycemia in a mitochondrial glycerol-3-phosphate dehydrogenase-deficient mouse. Diabetologia 2003; 46: 1394-1401.

29 Alfadda A, DosSantos A, Stepanyan Z, Marrif H, Silva JE. Mice with deletion of the mitochondrial glycerol-3-phosphate dehydrogenase gene exhibit a thrifty phenotype: effect of gender. Am J Physiol Regul Integr Comp Physiol 2004; 287: R147-R156.

30 Nishikimi M, Koshizaka T, Ozawa T, Yagi K. Occurrence in humans and guinea pigs of the gene related to their missing enzyme L-gulono-gammalactone oxidase. Arch Biochem Biophys 1988; 267: 842-846.

31 Yan J, Jiao Y, Li X, et al. Evaluation of gene expression profiling in a mouse model of L-gulonolactone oxidase gene deficiency. Genet Mol Biol 2007; 30: 322-329. 